\title{
O CONTEXTO RELIGIOSO-POLÍTICO DA CONTRAPOSIÇÃO ENTRE PIRRONISMO E ACADEMIA NA “APOLOGIA DE RAYMOND SEBOND”
}

\author{
José R. Maia Neto* \\ jrmaia@ufmg.br
}

RESUMO Montaigne faz um ataque pirrônico ao conceito acadêmico de verossimilhança ou probabilidade na Apologia de Raymond Sebond. O ataque é paradoxal porque Montaigne parece seguir o verossímil na própria Apologia e em diversos outros ensaios. Para resolver este problema exegético proponho uma dupla restrição do escopo do ataque à verossimilhança. Por um lado, mostro que o ataque visa mais a leitura epistêmica da verossimilhança proposta por Filo de Larissa do que ao conceito original de ordem exclusivamente prática de Carnéades. Por outro, situo-o em um contexto político-religioso bem especifico. $O$ ataque pirrônico à verossimilhança é a estratégia oferecida por Montaigne à rainha católica de Navarra e irmã do rei da França, Marguerite de Valois, para eventual uso nas polêmicas religiosas em sua corte majoritariamente protestante de Nérac. Esta contextualização soluciona também outros problemas exegéticos da Apologia, como o da defesa paradoxal de Sebond, a inconsistencia aparente entre as respostas de Montaigne às duas objeções feitas ao livro de Sebond, e o problema do fideísmo.

Palavras-chave verossimilhança acadêmica, pirronismo, Reforma, Contra-Reforma

* Departamento de Filosofia/FAFICH/UFMG. Bolsista do CNPq. Recebido em 21/06/2012. Aprovado em 27/07/2012. 
ABSTRACT In the Apology for Raymond Sebond, Montaigne launches a Pyrrhonian attack on Academic probability. However, Montaigne does follow probability in the Apology and other essays. In order to solve this exegetical problem I propose a double restriction of the attack. On the one hand, I show that it aims at Philo of Larissa's epistemic interpretation of the doctrine rather than at Carneades' original practical conception. On the other hand, I place the attack on a very specific historical context. Montaigne's Pyrrhonian attack on probability is a polemical strategy offered to Marguerite de Valois, the sister of the catholic king of France and wife of the protestant leader Henri de Navarre, to be used in the religious controversies in her predominant protestant court at Nérac. This context also solves other exegetical problems of the Apology such as Montaigne's paradoxical defense of Sebond, the apparent contradiction between the replies to the two objections to Sebond's book addressed by Montaigne, and the problem of fideism.

Keywords academic probability, Pyrrhonism, Reformation,CounterReformation

A contraposição entre pirronismo e academia na Apologia incide especificamente sobre a doutrina carneadiana do pithanon, traduzida por Cícero como probabile e verisimile. Montaigne reproduz uma crítica tradicional ao ceticismo acadêmico, largamente difundida por Agostinho. A crítica se vale desta segunda tradução ciceroniana: ${ }^{1}$ a noção de verossimilhança pressupõe a noção de verdade, sendo incompatível com a epoche e, portanto, com um ceticismo consistente e integral. ${ }^{2}$ Se há efetivamente uma diferença significativa entre estas duas tradições céticas antigas, a doutrina do probabilismo ou verossimilhança é a grande divisora de águas. ${ }^{3}$ Uma hipótese bastante aceita sobre o ressurgimento do pirronismo (ou surgimento do neopirronismo) no século I a.c. é a reação de Enesidemo, então membro da nova academia, à

1 "Mas tu, Carnéades ... quando dizes não conhecer nenhuma verdade, donde sabes que segue o verossímil?" (Agostinho, Contra os Acadêmicos, II.27).

2 Montaigne, Ensaios, II, 12, 561-562/343-344. As citações dos Ensaios serão indicadas com o número do livro, capítulo e páginas da edição Villey no original francês da PUF/Quadrige e na tradução brasileira da Martins Fontes. No caso das citações da Apologia, somente as páginas das duas edições serão indicadas.

3 A questão de haver ou não diferença relevante entre as duas escolas céticas é debatida desde a antiguidade até nossos dias. A literatura é imensa. Restrinjo-me a citar aqui o capítulo 33 do livro I dos Esboços de Sexto especificamente sobre esta questão e a tese, infelizmente ainda não publicada, de Roberto Bolzani, "Acadêmicos versus Pirrônicos", USP, 2003. 
leitura epistêmica da doutrina de Carnéades proposta por Filo de Larissa. ${ }^{4}$ Como sugere Montaigne, a influência desta tradição neoacadêmica é enorme. ${ }^{5}$ Ela decorre da grande influência no período de Cícero, que foi aluno de Filo; e de Agostinho, que responde a Cícero. É conhecida somente uma parte que creio mínima da influência do ceticismo acadêmico no pensamento moderno - em particular da doutrina da verossimilhança acadêmica - apesar do grande crescimento dos estudos históricos sobre o ceticismo moderno desde os trabalhos de Popkin. ${ }^{6}$ No caso que nos interessa aqui, como bem notou Flávio Loque $^{7}, \mathrm{o}$ ataque à verossimilhança na Apologia causa certa estranheza porque Montaigne a adota como critério de julgamento e de ação na própria Apologia e em diversos outros ensaios ${ }^{8}$. Para resolver este problema exegético da Apologia proponho uma dupla restrição do escopo do ataque à verossimilhança. Por um lado, mostrarei que o ataque visa mais a leitura epistêmica da verossimilhança proposta por Filo do que ao conceito carneadiano original. Por outro, situo-o em um contexto político-religioso bem específico. Esta contextualização soluciona também outros problemas ainda mais fundamentais que estudiosos da Apologia têm enfrentado como o problema da defesa paradoxal de Sebond, a inconsistência aparente das duas respostas de Montaigne às duas objeções e o problema do fideísmo. A minha hipótese é que o pirronismo de Montaigne na Apologia centra-se no ataque à verossimilhança acadêmica por ela ter sido apropriada por apologistas calvinistas. ${ }^{9} \mathrm{O}$ ataque pirrônico à verossimilhança é a estratégia oferecida por Montaigne à rainha católica de Navarra e irmã do rei da França Marguerite de Valois, para eventual uso nas polêmicas religiosas em sua corte majoritariamente protestante de Nérac. ${ }^{10}$

4 Cícero, Academica (Ac) II.7. Ver o resumo do livro desaparecido de Enesidemo, Escritos Pirrônicos, feito por Fócio, Biblioteca 212.169b-171a.

5 "esse partido teve o maior número de adeptos e os seguidores mais nobres" (502/254).

6 Esta linha de pesquisa foi iniciada por Schmitt (1972), mas interrompida pela crença, compartilhada por Schmitt e por Popkin, que após a tradução de Sexto a influência acadêmica teria diminuído significativamente. Para estudos recentes sobre esta influência que de fato não diminuiu, ver Paganini e Maia Neto 2009; Maia Neto 1997; 1999 (sobre Bayle); 2003 (sobre Foucher); 2009 (sobre Charron); Levy 2001 (sobre Pedro de Valência); Naya 2008 (sobre Omer Talon) e Lennon 2008 (sobre Descartes).

7 Ver: Ceticismo e Religião no Início da Modernidade, 2012.

8 Por exemplo, na Apologia, Montaigne diz que "De todas as ideias humanas e antigas no tocante à religião, parece-me haver tido mais verossimilhança [vray-semblance] e mais justificativa aquela que reconhecia Deus como um poder incompreensível" (513/270). Na camada [C], quando o contexto político-religioso do ataque ao probabilismo acadêmico já estava mais distante, diz, citando os Acadêmicos de Cícero, que o sábio é "forçado [contrainte]" a curvar-se a "circunstâncias somente prováveis [probables]" (505506/259). Como exemplo da adoção da verossimilhança em outro ensaio, pode-se citar Dos coxos: "Sou lerdo, e atenho-me um pouco ao concreto e ao verossímil [vray-semblable], evitando as censuras antigas" (III, 11, 1031/370).

9 Esta hipótese histórica está baseada, por enquanto, exclusivamente na Apologia.

10 Para uma leitura recente do ceticismo e do fideísmo da Apologia numa chave retórica que leva em conta as premissas da audiência (as damas de Navarra) e dos dois objetores de Sebond, ver Cardoso 2009. 
Inicialmente farei breves considerações históricas que sugerem ter sido a Apologia majoritariamente escrita ou para municiar Marguerite de Valois em seus debates com os huguenotes ou para registrar por escrito conselhos que Montaigne teria sussurrado oralmente nos ouvidos da bela e sedutora rainha Margot. ${ }^{11}$ Em seguida farei uma análise de passagens centrais da Apologia que comprovam a identificação da posição acadêmica aos protestantes e da pirrônica como estrategicamente oferecida por Montaigne à rainha para auxiliá-la a resistir à verossimilhança calvinista.

\section{O contexto histórico}

[A] Vós, por quem me dei ao trabalho de, contra meu costume, estender um corpo tão longo, não deixareis de defender vosso Sebond pela forma habitual de argumentar em que sois instruída diariamente, e exercitares nisso vosso espírito e vosso estudo; pois este último passe de esgrima só deve ser empregado como um recurso extremo. $(557-558 / 337)$

A edição Villey-Saulnier acrescenta a seguinte nota sobre a pessoa a quem Montaigne se dirige na passagem: "Segundo uma tradição, pouco antiga na verdade, este ensaio seria dirigido a Margarida de Valois, a futura esposa de Henrique de Navarra" (557/337).

Em primeiro lugar urge uma correção factual da maior importância. Marguerite já estava casada com Henri de Navarra, futuro Henri IV, quando a Apologia foi escrita. O casamento - seguido da famosa noite sangrenta de São Bartolomeu - foi celebrado em 1572 e Villey afirma que a Apologia não pode ser anterior a 1572, sendo, ainda segundo Villey, a maior parte (as passagens mais pirrônicas) provavelmente de 1576 . Villey indica ainda passagens que

11 Uma das principais rivais de Marguerite foi a Madame de Grammont, conhecida como a bela Corisande, amante do seu marido. Montaigne dedica a ela o capítulo 29 do Livro I dos Ensaios, que introduz "Vinte e Nove Sonetos de Etienne de La Boétie". Montaigne diz a Corisande que "estes [sonetos] possuem um não sei quê mais vivo e mais borbulhante, porque ele [La Boétie] os fez em sua mais verde juventude, e aquecido de um belo e nobre ardor que vos direi ao ouvido um dia, senhora" (I, 29, 196/293). Já o picante ensaio "Sobre os versos de Virgílio" (III, 5) teria sido escrito à intenção, segundo Nakam (1993: 299), de Marguerite: "Aborrece-me que meus ensaios sirvam às mulheres apenas como alfaia comum, e como alfaia de sala. Este capítulo (III, 5, que trata de amor e sexo) tornar-me-á da alcova» (III, 5, 847/93). Montaigne apreciava a companhia dos grandes: "Por minha natureza, não sou inimigo da agitação das cortes; nelas passei parte da vida e estou afeito a portar-me jovialmente em companhias importantes, contanto que seja com intervalos e na hora que me convier" (III, 3, 823/56). Além da influência sobre as damas através dos Ensaios, penso que Montaigne as influenciou diretamente, como ele fala dos eruditos de sua época. "Os eruditos [...] atualmente inundaram tão fortemente [...] as alcovas e os ouvidos das senhoras que, se elas não lhes retiveram a substância, pelo menos fazem ar disso" (III, 3, 822/53). Montaigne critica estes conselheiros que obscurecem os dotes intelectuais naturais das damas com a retórica e a lógica, recomendando a poesia, a história e a filosofa moral (III, 3, 823/55). 
não poderiam ter sido escritas antes de 1579. Mostro abaixo que 1579 é a data provável da redação, pelo menos da parte da Apologia que concerne mais diretamente a Marguerite, pois é quando a mesma se encontra na vizinhança de Montaigne.

Quanto à tradição de que a Apologia teria sido dirigida a Marguerite, ${ }^{12}$ ela é de fato relativamente recente no campo dos estudos montagnianos, mas remonta ao final da vida da rainha. Amaury Duval, editor de uma edição de 1827 dos Ensaios, afirma em uma nota que o "Vós" da passagem citada refere-se à Marguerite. Na nota relata possuir um exemplar dos Ensaios com uma anotação neste sentido feita por Pierre-Charles Jamet, bibliófilo do século XVIII, na qual diz ter tomado ciência da identidade da destinatária por Hilarion de Coste em pessoa, primeiro biógrafo e contemporâneo dos últimos anos da rainha, falecida em 1615. Este fato é relatado em 1923 pelo estudioso de Montaigne Joseph Coppin, que identifica nas Memórias da princesa uma passagem em que muito provavelmente se refere com grande entusiasmo ao Livro das criaturas de Sebond, cuja leitura lhe teria sido um caminho de devoção. ${ }^{13}$

Vários elementos históricos dão plausibilidade à tese Duval-Coppin. Montaigne diz no início da Apologia que seu objetivo foi o de socorrer as damas que viram "seu livro" [das criaturas], traduzido por Montaigne, ${ }^{14}$ atingido "por duas objeções principais" que examinarei adiante. Marguerite é a principal dama de Navarra e uma das principais da França. A descrição do poder da destinatária corresponde perfeitamente à sua situação: "Vós que, pela autoridade que vossa grandeza vos traz e ainda mais pelas vantagens que as qualidades mais vossas vos dão, podeis com um piscar de olhos comandar quem vos aprouver" (558/338-339). Marguerite era conhecida como dotada de qualidades físicas e espirituais excepcionais. Sua chegada a Gascogne e

12 Até onde sei a única dama, fora Marguerite, que já foi apontada na literatura como a destinaria da Apologia é a irmã de Henri de Navarra, Catherine de Bourbon (ver Norton 1904: 51ff). Mostro abaixo que a defesa de Sebond visa a defesa do catolicismo romano. Como Catherine era protestante ela não pode ser a destinatária da Apologia.

13 A passagem em questão se refere ao período em que Marguerite estava presa no castelo do seu irmão em Paris, Henri III, impossibilitada de juntar-se ao marido na Gascogne. " ayant passé le temps de ma captivité au plaisir de la lecture, où je commençay lors à me plaire ; n'ayant cette obligation à la fortune, mais plustost à la providence divine, qui dès lors commença à me produire un si bon remede pour le soulagement des ennuis qui m'estoient preparez à l'advenir. Ce qui m'estoit aussi un acheminement à la devotion, lisant en ce beau livre universal de la nature les merveilles de son créateur, que toute ame bien née, faisant de cette congnoissance une eschelle de laquelle Dieu est le dernier et le plus haut eschelon, ravie, se dresse à l'adoration de cette merveilleuse lumiere et splendeur de cette incomprehensible essence ». Passagem citada por Coppin (1923: 59) que coloca em itálico os trechos que mais evidenciam tratar-se do Livro das Criaturas. Ver também Limbrick (1990) e Rigolot (1990).

14 Marguerite provavelmente leu a tradução de Montaigne, publicada em 1569. A referência implícita de Marguerite à Teologia Natural acima citada é de 1576. Ver Viennot (2005: 117). 
estabelecimento em Nérac com suas damas teve grande repercussão na época, e não somente na França. Shakespeare, por exemplo, escreveu uma comédia ambientada na corte de Nérac (Love's Labours Lost) que retrata o choque entre os nobres protestantes, liderados por Henri, moralmente rigorosos, mas um tanto broncos e ingênuos nas coisas do amor por um lado e as damas católicas recém-chegadas de Paris, lideradas por Marguerite, grandes especialistas na arte de sedução cortesã. ${ }^{15}$ A descrição por Montaigne da destinatária da Apologia resume bem a comédia de Shakespeare, na qual a princesa controla Ferdinand de Navarra (que representa Henri) e seus gentilshommes com um piscar de olhos.

Marguerite chega inicialmente a Bordeaux em outubro de 1578, onde é recebida com grande pompa pelos nobres da cidade. Em fevereiro de 1579 participa ativamente de uma conferência política reunindo católicos e protestantes em Nérac, onde ela estabelece sua corte junto ao marido até janeiro de $1582 .{ }^{16}$ Sua corte atraiu os grandes eruditos e poetas da região. Um destes poetas, Guy du Faur de Pibrac (1529-1584), conselheiro do rei como Montaigne e amigo pessoal do autor da Apologia, foi tesoureiro de Marguerite por quem se apaixonou. ${ }^{17}$ Embora não haja, até onde sei, documentos históricos que atestem a presença física de Montaigne em Nérac entre a chegada de Marguerite no final de 1578 e a publicação da primeira edição dos Ensaios (incluindo a Apologia) em 1580, ${ }^{18}$ os historiadores são unânimes em apontar a verossimilhança da frequentação de Montaigne da corte de Marguerite. ${ }^{19}$ Montaigne era então Chevalier de Chambre, tanto do

15 "Grâce à l'inventaire dressé à Nérac le 5 novembre 1578, il est facile d'imaginer les salles et chambres de l'ancienne forteresse pendant le séjour de la fille des Valois. Aux murs étaient pendues de riches tapisseries de velours et de soie brodées et armoriées [...]. Les tables et buffets étaient recouverts de tapis, et des rideaux de damas et de soie à franges d'or pendaient aux fenêtres [...]. Dans ce décor luxueux, la souveraine vécut entourée de plus de trente dames et filles d'honneur venues du Louvre [...] et de gentilshommes français et gascons. Marguerite de Valois, âgée de vingt-cinq ans, était dans tout son éclat ; 'elle ne fut jamais si belle ni si joyeuse' écrit alors Mme de Picquigny, l'une de ses dames d'honneur » (Droz 1964: 6).

16 Ver Viennot (2005: 143-183)

17 Ver Viennot (2005), p. 155. Montaigne elogia Pibrac no ensaio "Da Vanidade": "O bom senhor de Pibrac, que acabamos de perder: um espírito tão bem nascido, de ideias tão saudáveis, de comportamento tão ameno. Essa perda, e a do senhor de Foix que sofremos simultaneamente, são perdas importantes para nossa coroa. Não sei se resta à França para substituí-los uma outra dupla igual a esses dois gascões em sinceridade e em capacidade para aconselhar nossos reis" (III, 9, 957/258).

18 Há documentos históricos que atestam um ativo contato diplomático entre Montaigne e Marguerite durante o período que vai do retorno de Montaigne da Itália para assumir a prefeitura de Bordeax em 1581 até a partida da rainha de Nérac no início de 1582 (ver Viennot 2005: 576n10).

19 "Marguerite organise alors autour d'elle une vie littéraire brillante [...] elle attire à Nérac tout ce que la région compte de poètes et d'artistes, qu'ils soient catholiques ou huguenots. [...] C'est l'époque [...] où elle rencontre Montaigne qui en voisin se rend souvent au château » (Viennot 2005 : 159-160). "Au près d'Henri de Navarre, de Marguerite, de Corisande, il joue un rôle actif de conseiller, qui lui convient et qui lui plait" (Nakam 1993: 373). Ver também Droz (1964: 28) e Gruen (1855: 395). 
rei católico da França Henri III, irmão de Marguerite, como do rei protestante de Navarra. Marguerite, como diz Montaigne, era estudada e tinha espírito (558/337). Este juízo era compartilhado por alguns dos "principais" huguenotes. ${ }^{20}$ Além de Sebond, Marguerite conhecia o pensamento de outros filósofos, especialmente da tradição neoplatônica, e era católica convicta. É difícil imaginar que não tenha sido intelectualmente desafiada por apologistas huguenotes a sustentar o catolicismo romano. ${ }^{21}$ Uma sua eventual conversão à religião do marido seria um trunfo enorme para o partido protestante. ${ }^{22}$ Entre a chegada de Marguerite na Gascogne e a publicação da Apologia decorreu quase um ano, tempo suficiente para que Montaigne "socorresse" [secourir] (440/163) Marguerite e suas damas católicas nas controvérsias a que se expuseram ao instalarem-se na corte protestante de Henri de Navarre. ${ }^{23}$ Dois dos maiores protestantes que se engajaram em controvérsias teológicas públicas oficiais com teólogos católicos, Du Plessis-Mornay e Agrippa d'Aubigné, eram conselheiros de Henri de Navarra na época. Aubigné, poeta mais frequente no caderno de poesias que Marguerite guardava em Nérac, afirma que a rainha não gostava dele por, entre outros motivos relacionados à intrigas de corte, "não ser complacente com suas vontades". ${ }^{24}$

A Apologia se ajusta a tal designío? Como observa Villey, os dois primeiros livros dos Ensaios não têm - sobretudo na primeira edição de 1580 - tanto o desígnio da pintura de si como o terceiro livro. O objetivo original dos dois primeiros livros é o "benefício particular de meus parentes e amigos; para que, ao me perderem (do que correm o risco dentre em breve), possam reencontrar nele alguns vestígios de minhas tendências e humores"

20 Em suas Memórias, Marguerite afirma que "les principaux de la religion [huguenote] m'estimaient avoir quelque jugement” (citado por Grüen 1855: 171).

21 O relato que Marguerite faz de sua estadia em Nérac é bastante favorável, não indicando qualquer assédio importuno de apologistas (ver Viennot 2005: 159). Certamente as tentativas de conversão se deram dentro do debate intelectual amigável, debate este bem ao gosto de Marguerite (Viennot 2005: 292). Qualquer agressividade por parte dos pastores nos debates com católicos era formalmente proibida pelas igrejas protestantes (Kapler 2011: 45).

22 Em carta de Jeane d'Albert ao seu filho Henri, a rainha diz que se Marguerite "embrasse la religion, je puis dire que nous sommes les plus heureux du monde", mas, continua a rainha protestante, "si ele demeure opiniâtre en sa religion [...] y étant affectionnée comme l'on dit qu'elle est, [...] ce mariage ne [sic] fût la ruine [...] de nos amis et de nos pays" (carta citada por Viennot 2005: 56).

23 Como indiquei acima, segundo Villey (436-437/157-159) a versão da Apologia publicada em 1580 foi escrita ao longo de anos sucessivos. Os trechos mais antigos, aqueles que contêm as declarações mais pirrônicas de Montaigne, datariam de 1576 e os mais tardios (alusão à sua doença e às leituras recentes) seriam de 1578. Cabe observar que 1576 (quando Montaigne escreve as frases céticas na sua biblioteca, impressionado pela leitura de Sexto) é o terminus a quo e não a data certa da escrita dos trechos mais pirrônicos, que podem perfeitamente ter sido escritos durante a permanência de Marguerite na Gascogne, ou seja, entre setembro de 1578 e agosto de 1579.

24 Citado por Viennot (2005: 186). Sobre as conferências públicas com prelados católicos de Du PlessisMornay e Agrippa d'Aubigné, ver Kapller (2011: 321 - 344 e 403-404). 
(I, Ao leitor, 3/3). Este objetivo se desdobra em dois outros compatíveis. O simples registro em escrito da pessoa Montaigne, como souvenir na sua ausência e, mais raramente, o registro de conselhos específicos a amigas. $\mathrm{O}$ ensaio II.37/“Da semelhança dos filhos com os pais" tem o primeiro objetivo. Ele é dedicado à Madame de Duras por esta o ter visitado quando escrevia o ensaio. ${ }^{25}$ Madame de Duras era a "confidente e favorita" da rainha de Navarra, a quem acompanhou na maioria das viagens pela França, incluindo esta a Gascogne quando encontrou Montaigne. ${ }^{26}$ No caso de Marguerite, evidentemente as conversações seriam no château da rainha, mas não menos amigáveis e ainda mais necessitadas de um registro escrito, pelo caráter de conselho que tem. Com efeito, dois outros ensaios de Montaigne dedicados a damas de suas relações constituem conselhos bem específicos, como o dado a Marguerite na Apologia. O ensaio II.8/“Da afeição dos pais pelos filhos" é dedicado à Madame d'Estissac então viúva e aparentemente avara com o seu filho. Montaigne lhe aconselha a deixar o filho gerir os bens da família. $\mathrm{O}$ ensaio I.26/“Da educação das crianças" é dedicado à Madame de Foix. Ela está grávida e Montaigne lhe dá conselhos sobre a educação do futuro filho. ${ }^{27}$ Mas, poder-se-ia questionar, se Marguerite é a destinatária da Apologia porque o seu nome é omitido, diferentemente dos nomes das outras damas a quem Montaigne se dirige nos Ensaios? É preciso distinguir destinatária da pessoa a quem se dedica uma obra. O ensaio II.8 não é destinado à Madame de Duras, mas somente a ela dedicado. O mesmo ocorre com a introdução aos versos de La Boétie, dedicados - mas evidentemente não dirigidos - a Madame de Grammont. Várias publicações de poetas, filósofos e eruditos foram dedicadas a Marguerite, seja pelo simples fato dela ser uma grande autoridade e patrona das artes, seja pelos seus interesses mais específicos, como o neoplatonismo no campo da filosofia. ${ }^{28}$ Outras obras foram dirigidas a ela - sendo algumas explicitamente dedicadas, outras não - como por exemplo as obras escritas por pretendentes e amantes. ${ }^{29}$ A hipótese Duval-Coppin não é que a Apologia

25 "Senhora, encontrastes-me nesse passo recentemente quando me viestes ver. Como pode ser que estas inépcias caiam um dia em vossas mãos, quero também que elas deem testemunho de o autor se sentir muito honrado com o favor que lhes fareis. Reconhecereis aqui aquela mesma postura e aquele mesmo ar que vistes em sua frequentação" (II, 37, 783/673-674).

26 Ver Viennot (2005: 186).

27 Segundo Nakam (1993: 299n), de fato uma filha, cuja madrinha é Marguerite de Valois. Segundo o estudioso francês, o batizado da menina em 2 de dezembro de 1583 foi uma das várias ocasiões em que Montaigne se encontrou pessoalmente com Marguerite.

28 François de Foix dedica a Marguerite sua tradução comentada da obra neoplatônica Pimandre de Mercure Trimegiste de la philosophie chrestienne (1574) (ver Droz 1964:29) e Guy Le Fèbvre de la Boderie Ihe dedica sua tradução do comentário do Banquete de Platão por Ficino em 1578 (ver Viennot 2005: 310).

29 Por exemplo, Jean de Gontaut-Biron, barão de Salignac. Próximo de Henri de Navarra, diz em suas Memórias: "Je pris congé du roy de Navarre (em 1580) [...] j'avois, outre cela, un sujet qui me convioit à 
é dedicada à Marguerite, em cujo caso a omissão do seu nome exigiria uma explicação, mas que a Apologia é dirigida a Marguerite, como um conselho privado cuja divulgação pública da identidade da destinatária poderia ser até indevida. ${ }^{30}$

A hipótese de que Marguerite de Valois é a destinatária original da Apologia não é, portanto, incompatível com a natureza dos Ensaios. É compatível, também, com a singularidade da Apologia entre os Ensaios. Em primeiro lugar, a desproporção do seu tamanho. Na primeira passagem em que se dirige a Marguerite, Montaigne diz que ela foi a pessoa por quem ele se deu "ao trabalho de, contra o [s]eu costume, estender um corpo tão longo" (557/337). Outra especificidade da Apologia no corpo dos Ensaios é o fato de tratar de questões teológicas (440/164). Tais questões são tratadas justamente porque são essenciais nos debates para os quais Marguerite é assistida. Montaigne deixa claro que não trataria de tais questões e não faria um ensaio tão grande se não fosse pela solicitação de Marguerite e suas damas, o que indica tratar-se de alguém com autoridade soberana sobre ele.

Se Coppin está certo sobre a extensão da afeição de Marguerite pelo Livro das Criaturas de Sebond, este foi, muito provavelmente, um dos textos em que Marguerite apoiava a sua fé católica, pois, como diz Montaigne na Apologia, Sebond busca nele "vérifier" todas as doutrinas católicas, especialmente a eucaristia, principal alvo dos calvinistas. ${ }^{31}$ É natural que Marguerite recorresse a seu súdito católico, vizinho e tradutor do Livro das Criaturas para defendê-lo dos ataques calvinistas. Como Marguerite apoia seu catolicismo em Sebond, o socorro que Montaigne presta às damas que veem seu Sebond questionado visa, em última instância, a defesa do catolicismo.

m'éloigner dudict roy, pour m'éloigner des passions qui tirent nos ames et nos corps après ce qui ne leur porte que honte et dommage » (citado por Droz 1964:14).

30 Rigolot (1990: 265-266) considera somente o contexto religioso e não o político ao colocar esta objeção. A explicação do ocultamento do nome de Marguerite deve ser buscada no cenário pantanoso das disputas políticas da época. Embora católica, Marguerite tinha péssimas relações com o irmão, Henri III, a quem Montaigne deveria servir acima de qualquer outra pessoa e a quem entregou pessoalmente um exemplar da primeira edição dos Ensaios (cf. Les Essais, p. XLV).

31 Ver Sebond (1569). Os capítulos sobre a eucaristia são o 285 e o 293. Neste último, Sebond mostra como o corpo de Cristo pode permanecer indivisível em vários lugares ao mesmo tempo. No primeiro, articula o sacramento com a sua teoria mística neoplatônica do amor, particularmente apreciada por Marguerite (ver nota 28 acima). Cito a análise de Alain Guy : "Raimond Sebond expose [...] systématiquement tout l'apport des Sacrements. [...] L'Eucharistie, surtout (par laquelle 'l'amant se nourrit de l'aimée'), reçoit un traitement extrêmement approfondi et puissant (on songe aux pages d'Unamuno, à propos des fidèles atteignent l'unité; ils ne forment plus qu'un seul corps, car la communion est le sacrement de l'amour, qui attire en nous la chaleur spirituelle. La réflexion sebondienne sur la transsubstantiation ne manque pas de richesse. 'Les paroles du Christ font ce qu'elles signifient [...]; le pain et le vin sont changés en corps et en sang du Christ; notre âme s'aliment du pain spirituel, comme notre corps a besoin du pain matériel; la communauté des chrétiens resserre ainsi son unité fraternelle et intime. A ce niveau, l'Eucharistie transmue notre être, du visible à l'invisible'» (Guy 1990: 35). 


\section{O contexto das posições filosóficas}

As duas objeções a Sebond a que Montaigne respondeu na Apologia são as seguintes. A primeira "é que os cristãos estão errados em querer apoiar com razões humanas sua crença, que só se concebe por fé e por uma inspiração particularizada da graça divina" (440/163-164). A segunda é que os "argumentos [de Sebond] são fracos e inadequados para demonstrar [vérifier] o que ele pretende, e dispõem-se a atacá-los facilmente" (448/175). Estas duas objeções são mutuamente conflituosas. A primeira recusa o papel da razão na apologética religiosa ao passo que a segunda tacitamente aceita tal papel, limitando-se a mostrar a inadequação da argumentação de Sebond para conferir verossimilhança às doutrinas católicas. Uma vez que estas duas objeções derivam de concepções distintas da relação entre razão e fé, elas confirmam a distinção que Montaigne faz entre os autores das duas objeções. ${ }^{32}$ As respostas que Montaigne dá a elas são - se não contraditórias - certamente conflituosas. Na resposta à primeira objeção, Montaigne defende o papel embora limitado - da razão na apologética religiosa ao passo que a estratégia central da resposta à segunda objeção é radicalizar a insuficiência da razão, não somente em matéria apologética, mas em todas as matérias. Esta tensão se desfaz se pensarmos cada resposta como ad hominem, isto é, como válida somente para cada objetor.

Quem seriam estes objetores? No contexto das guerras de religião da época é plausível associar cada objetor a um dos partidos contrários que não eram os de Montaigne. Estes partidos contrários eram o protestante, liderado por Henri de Navarra, e a Santa Liga, fundada pelo duque de Guise para exterminar a religião calvinista do solo francês. ${ }^{33}$ Montaigne era do partido católico, mas moderado, próximo dos "politiques", que buscava uma solução conciliada para o conflito religioso. ${ }^{34}$

Os autores da primeira objeção conformam-se ao figurino dos membros da Liga. São católicos "piedosos” e "zelosos" (440/164) que não querem

32 Montaigne distingue bem os objetores ao dizer que na primeira objeção "parece que há um fervor de piedade" (440/164) ao passo que os autores da segunda objeção "são mais perigosos e mal-intencionados que os primeiros" (448/175).

$33 \mathrm{O}$ duque de Guise foi pretendente de Marguerite antes de ela se casar com Henri de Navarra (Viennot 2005: 51-52). Os opositores político-religiosos foram também, em certo sentido e por algum tempo, rivais amorosos.

34 "Montaigne sert la monarchie aux côtés des Politiques. Il partage les idées du conseiller Paul de Foix, du conseiller Henri de Mesmes, de Loisel, de de Thou. Si les Essais de 1580 insistent sur l'antidogmatisme religieux et la diversité des opinions, le livre III transmet les thèmes nationaux les plus marquants des années de la Ligue : la candidature d'Henri de Navarre, l'anarchie de la Ligue et le rôle de Paris dans la réalisation de l'unité nationale. L'opposition de Montaigne à la Ligue se manifeste à Bordeaux et dans les Essais " (Nakam 1993:430). 
disputar com os protestantes no terreno da razão. ${ }^{35}$ Pouco importa se a versão calvinista do cristianismo é mais verossímil do que a católica. A fé não somente tem outro fundamento (posição agostiniana com a qual Montaigne concorda), mas até dispensa a razão (posição não agostiniana da qual Montaigne discorda). Assim, é indiferente para estes objetores a questão de se os argumentos pró-católicos de Sebond são ou não válidos. Mais importante do que buscar persuadir os huguenotes com argumentos é impor a ortodoxia católica pela espada.

Montaigne responde, em primeiro lugar, defendendo como "uma iniciativa muito bela e muito louvável adaptar ao serviço de nossa fé os instrumentos naturais e humanos que Deus nos deu" (441/164). Montaigne aconselha Marguerite a seguir preferencialmente esta via apologética tradicional quando lhe apresenta a via extrema pirrônica, a ser empregada somente "como um recurso extremo": "Vós [...] não deixareis de defender vosso Sebond pela forma habitual de argumentar em que sois instruída diariamente, e exercitareis nisso vosso espírito e vosso estudo" (557-558/337). ${ }^{36}$ Dada a plasticidade da razão que, como veremos na resposta à segunda objeção, é capaz de produzir verossimilhança sobre não importa o que, Montaigne parece dizer aos zelosos da Liga: "Não devemos abandonar a razão para os huguenotes na disputa religiosa porque não é verdade que os argumentos verossímeis são só os calvinistas. Nós também, católicos, podemos produzir - e Sebond efetivamente produziu - argumentos a favor de nossas doutrinas tão verossímeis quanto os calvinistas". ${ }^{37} \mathrm{Em}$ segundo lugar, partindo para a ofensiva, Montaigne denuncia a arrogância e a superstição associadas a esta objeção “zelosa”. A arrogância está na pretensão da própria fé do objetor estar fundamentada na graça divina, dispensando os frágeis instrumentos racionais naturais humanos. ${ }^{38} \mathrm{Na}$ verdade o "zelo piedoso" se efetiva em ação

35 No ensaio "Defesa de Sêneca e de Plutarco" (II, 23), Montaigne discute o paralelo feito na época entre, por um lado, Charles IX e o Cardeal de Loraine (tio de Henri de Guise e principal mentor intelectual da Liga) e, por outro, Nero e Sêneca. Sobre a associação entre o Cardeal e o estoico, Montaigne fala do primeiro: "embora eu esteja entre os que muito prezam seu espírito, sua eloquência, seu zelo para com a religião (son zele envers sa religion) e o serviço do seu rei [...] não considero sua capacidade muito próxima da de Sêneca, nem sua virtude tão pura e total, nem tão sólida" (II, 23, 722/582).

36 A efetividade da via apologética racional tradicional é exemplificada no caso do próprio Sebond, cujos argumentos teriam afastado "um homem de grande autoridade" dos "erros da incredulidade" (447448/174).

37 "mesmo que [os argumentos de Sebond] sejam [...] tomados como ideias puramente humanas para combater os que se precipitam nas apavorantes e horríveis trevas da irreligião, ainda assim eles se mostrarão tão sólidos e tão firmes como nenhum outro da mesma condição que se lhes possa opor" $(447 / 174)$.

38 "se nos ligássemos a Deus por ele, não por nós [...] o amor da novidade, a imposição dos príncipes, a boa fortuna de um partido, a mudança irrefletida e fortuita de nossa ideias não teriam a força de sacudir e alterar nossa crença; não a deixaríamos tremer à mercê de um novo argumento e ante a persuasão, 
política intolerante, violenta e sediciosa que, ao contrário de revelar a força da fé, mostra a instrumentalização da religião para fins meramente políticos. Montaigne fustiga então os membros da Liga. Estes que alegam uma base sobrenatural para a sua fé desmentem tal base pelas suas ações, em tudo semelhantes à dos heréticos huguenotes a que se opõem de forma tão radical. Os membros da Liga "empregam [a religião] de maneira tão semelhante [aos protestantes] em seus violentos e ambiciosos projetos, caminham numa marcha tão igual [aos protestantes] em desregramento e injustiça que tornam duvidosa e difícil de crer sua pretensa diversidade de opiniões" $(443 / 167) .{ }^{39}$ Mesmo estas opiniões, ao contrário de fundarem-se na graça, respondem a interesses meramente humanos. Montaigne cita justamente a troca de opiniões entre protestantes e católicos da Liga após a morte de Henri III. Os huguenotes defendiam o direito de rebelião em nome da religião até que o direito da sucessão recaiu sobre Henri de Navarra. A partir daí passaram a defender o legalismo sucessório com o mesmo ardor exibido até então pelos católicos da Liga que, por sua vez, passaram a defender o direito da rebelião em nome da religião. ${ }^{40}$

A identificação dos primeiros objetores como membros da Santa Liga fica aqui a título de sugestão. Os elementos textuais que apontam nesta direção são menores do que os que permitem identificar os autores da segunda objeção ao outro partido extremado na época, os huguenotes. ${ }^{41}$ Uma leitura atenta da Apologia não deixa dúvida que a segunda objeção à Sebond visa a religião católica de Marguerite e sua entourage. Parece-me também evidente que a posição do objetor não é o que entendemos hoje por ateísmo. Em primeiro lugar simplesmente porque provavelmente não havia na Europa da época ateus no sentido de descrentes do Deus judaico-cristão. ${ }^{42} \mathrm{E}$ ainda que existissem ateus na época de Montaigne, ${ }^{43}$ é impossível que o autor da Apologia se esteja referindo aqui a "ateísmo" como o concebemos hoje, pois tal posição

nem mesmo de toda a retórica que jamais existiu; resistiríamos a essas ondas com uma firmeza inflexível e imóvel" (441/165). Casos de conversão de católicos zelosos ao calvinismo derrubam a pretensão de um fundamento sobrenatural da crença religiosa.

39 O exemplo é da camada [C] dos Ensaios, quando a Liga estava em declarada guerra civil com o poder monárquico legal. Mas a sua formação data de 1576. Ver também III, 10, 1013/343-344: os huguenotes são imitados e superados em extremismo, zelo, paixão e irracionalidade pelos membros da Liga.

40 Ver nota dos editores da edição Villey-Saulnier (443n15/168n11). Cabe especificar que são os católicos da Liga "que se armam contra o regime soberano e que afirmam seu direito de derrubá-lo do trono".

41 A resposta que Montaigne dá aos autores da primeira objeção é curta - comparativamente a que dá aos autores da segunda - e irrelevante para a questão que me interessa neste artigo, a contraposição entre pirrônicos e acadêmicos.

42 Ver Febvre (1942) e Kristeller (1968).

43 Como pretende Wooton (1988: 706-707) que toma - erradamente a meu juízo - "ateu" e "ateísmo" na Apologia como os primeiros registros do termo no sentido de descrente e não meramente herético. 
certamente não existia na dimensão social diagnosticada. ${ }^{44} \mathrm{~A}$ designação por Montaigne deste segundo objetor como "ateu" ou de sua objeção como "ateia" ${ }^{45}$ precisa ser entendida no sentido que o termo tinha na época, a saber, como herético em relação à crença religiosa objetada. ${ }^{46}$ Montaigne lembra que quando o pai recebeu um exemplar do Livro das Criaturas do erudito Pierre Bunel, este recomendou a utilidade do mesmo na ocasião, "foi quando as novidades de Lutero começavam a entrar em voga e a abalar em muitos lugares nossa antiga crença. Nisso ele tinha uma opinião muito acertada, prevendo pelo raciocínio que aquele início de doença facilmente degeneraria num execrável ateísmo" (439/161-162). Este "ateísmo" de que fala Montaigne é, como ele explica na sequência, a consequência lógica da subordinação da crença religiosa ao julgamento pessoal ${ }^{47}$ Descreve o racionalismo religioso do reformador que só toma como verdadeiros aqueles dogmas cristãos cuja verossimilhança é atestada pela própria razão. ${ }^{48}$ Outra evidência que os adversários visados são racionalistas cristãos é o fato de Montaigne comparálos aos maniqueístas cristãos combatidos por Agostinho. "[C] Pois Santo Agostinho, arrazoando contra estas pessoas, tem a oportunidade de criticar sua injustiça por considerarem falsas as partes de nossa crença que nossa razão fracassa em estabelecer" (449/176) ${ }^{49}$ Os racionalistas cristãos heréticos da época de Montaigne são os protestantes que consideram falsas as partes da crença católica desprovidas de verossimilhança. Isto é precisamente

44 "perigosa peste que se espalha diariamente em vossas cortes" (559/340).

45 "um ateísta compraz-se em desviar para o ateísmo todos os autores, infectando com seu próprio veneno a matéria inocente" (448/175). Outra passagem em que o termo "ateísmo" aparece é citada logo a seguir.

46 "Ever since the middle of the sixteenth century, theological polemists were prone to brand as atheistic any opinion differing from their own" (Kristeller 1968: 236).

47 Um controversialista católico do século XVII indaga: "como se pode dar o nome de religião a uma seita que só ama a liberdade [...] e que no fundo, por suas máximas, prepara o caminho para o ateísmo" (citado por Kappler 2011: 239). Bossuet define bem este sentido de herético: "L'hérétique est celui qui a une opinion et c'est ce que le mot signifie. Qu'est-ce à dire: avoir une opinion? C'est suivre sa propre pensée et son sentiment particulier. Mais le catholique [...] sans avoir le sentiment particulier [...] suit sans hésiter celui de l'Eglise » (citado por Kappler 2011: 266-267n15).

48 "depois que alguns artigos de sua religião foram postos em dúvida e na balança, [o vulgo] não tarda em jogar comodamente na mesma incerteza todas as outras partes de sua crença, que não tinham dentro dele mais autoridade nem fundamento do que aquelas que lhe foram abaladas" (439/162). Se havia ateus na época de Montaigne, certamente não os havia na época de Sebond, cujos adversários são também taxados por Montaigne de "ateístas" (440/163). Como Sebond busca dar plausibilidade racional ao credo católico, seus objetores são racionalistas em matéria religiosa, como os protestantes da época de Montaigne, que rejeitam alguns destes dogmas (sobretudo a eucaristia e a transubstanciação) por considerá-los não racionais.

49 Ver Confissões VI, 5 onde Agostinho, respondendo aos maniqueístas, diz que não devemos dar ouvidos aos que dizem que como a verdade da Escritura não pode ser demonstrada não devemos dar assentimento ao seu conteúdo. Os maniqueístas contemporâneos de Agostinho não eram ateus, mas cristãos que buscavam conciliar racionalmente a existência de Deus com a existência do mal através da doutrina do duplo princípio, da existência da matéria independentemente da vontade e criação de Deus. 
indicado por Marie de Gournay em seu prefácio aos Ensaios, defendendo o catolicismo de Montaigne: "Quem poderia suportar estes novos Titãs do século, estes alpinistas do Céu, que pensam poder conhecer Deus por seus meios e circunscrever Deus, suas obras e as próprias crenças nos limites da própria investigação e razão, não querendo acolher nada como verdadeiro que se não lhes apareça como verossímil [vray-semblable]?"50

Os autores da segunda objeção são chamados de "novos doutores" por Montaigne logo em seguida à referência à Marguerite acima citada (559/340). Estes objetores são, portanto, teólogos da religião reformada. Isto indica que Marguerite se vale de Sebond para defender seu credo católico e que os apologistas huguenotes que frequentam a corte do marido como Du PlessisMornay e d'Aubigné atacam Sebond no sentido de mostrar a invalidade dos seus argumentos a favor dos dogmas católicos. A arma pirrônica que Montaigne oferece à rainha deverá ser usada caso "alguns desses novos doutores decidir fazer-se de engenhoso em vossa presença [isto é, buscar convencê-la da maior verossimilhança das doutrinas calvinistas], à custa de sua salvação e da vossa [isto é, à custa da salvação do calvinista herético e da rainha, caso esta seja persuadida pela verossimilhança das heresias]" (559/340). O conselho principal de Montaigne é muito claro: Marguerite deve permanecer católica. "Mantende-vos na rota comum [...]. Aconselho-vos, em vossas ideias e em vossas argumentações tanto quanto em vossos costumes e em qualquer outra coisa, a moderação e a temperança, e a fuga da novidade e da estranheza" (558/338).

Várias passagens da Apologia identificam a Reforma como "novidade". ${ }^{51}$ Outras passagens que também revelam a identidade dos autores da segunda objeção poderiam ser citadas. Por exemplo, a crítica à religião puramente espiritual de Numa visa os reformadores (513/271). Idem a extensa crítica às tentativas de limitação da potência divina à capacidade racional humana. ${ }^{52}$ Uma das passagens nas quais Montaigne se refere, na minha opinião,

50 Prefácio de Marie de Gournay não paginado aos Les Essais de Michel seigneur de Montaigne (Paris: Augustin Courbé, 1652). Segundo Viennot (2005: 290), Marie de Gournay foi bibliotecária de Marguerite durante o último período da vida da rainha em Paris, entre 1606 e 1615.

51 Por exemplo, na passagem já citada quando Montaigne recorda a ocasião da utilidade de Sebond: "quando as novidades de Lutero começavam a entrar em voga e a abalar em muitos lugares nossa antiga crença" (439/161). "[É] o orgulho [...] que faz [o homem] abraçar as novidades [...] preferir ser mentor e preceptor de erro e de mentira a ser discípulo na escola da verdade e deixar-se levar e conduzir pela mão de outrem ao caminho batido e reto" (498/248). "[O] amor à novidade, a rebeldia, a desobediência" "nascem" da "impressão da opinião e ciência que pensamos ter das coisas" (503/255).

52 "Nas disputas que acontecem atualmente em nossa religião, se pressionardes demais os adversários, eles vos dirão abertamente que não está no poder de Deus fazer que seu próprio corpo esteja no paraíso e na terra e em vários lugares ao mesmo tempo" (527/292). A negação da eucaristia seria um aspecto do que Montaigne chama de "ateísmo" da religião reformada. 
exclusivamente à Reforma é citada por Popkin ${ }^{53}$ como chave da associação entre o ceticismo e o fideísmo na Apologia. Segundo Montaigne, o pirronismo

apresenta o homem nu e vazio, reconhecendo sua fraqueza natural, apropriado para receber do alto uma força externa, desguarnecido de ciência humana e portanto mais apto para alojar em si a divina, anulando seu próprio julgamento a fim de dar mais espaço para a fé, $[\mathrm{C}]$ nem descrendo $[\mathrm{A}]$ nem estabelecendo algum dogma contra as observâncias comuns; humilde, obediente, disciplinado, zeloso; inimigo jurado da heresia e consequentemente isentando-se das ideias irreligiosas e vãs introduzidas pelas falsas seitas. $(506 / 260)$.

O tex to deixa claro que esta utilidade do pirronismo, pelo menos na primeira edição dos Ensaios, ${ }^{54}$ não é a de conduzir um ateu ou pagão ao cristianismo. A verdade ou falsidade - ou o benefício ou malefício - do cristianismo não está em questão na Apologia. ${ }^{55} \mathrm{~A}$ utilidade reivindicada é a manutenção do católico na religião católica, isto é, evitar sua conversão à religião reformada. O que o pirronismo favorece no contexto é a não utilização de nossa razão como critério de crença religiosa - como fazem os protestantes. ${ }^{56}$ Proponho assim uma correção parcial de Popkin que contextualiza a posição de Montaigne na Contra-Reforma, mas também lhe atribui, a meu ver de forma anacrônica, uma visão fideísta do cristianismo. Popkin erra ao concordar com Villey que a Apologia teria sido escrita - em suas partes substanciais - "em 1575-1576, quando Montaigne, através do estudo dos escritos de Sexto Empírico, estava passando pelo trauma extremo de ver todo seu mundo intelectual se dissolver na dúvida completa". Não acho que a Apologia seja "o resultado d[a] crise pyrrhonienne pessoal [de Montaigne]"57 - pelo menos não o seu resultado imediato - nem que "juntamente com este desdobramento [...] vigoroso da crise pyrrhonienne, Montaigne constantemente introduz seu tema fideísta: a dúvida completa a nível racional, combinada com uma religião baseada na fé exclusivamente, que nos é dada não por nossas capacidades mas somente pela Graça de Deus" ${ }^{\text {"5 }}$. Como já propus, a Apologia foi escrita majoritariamente em 1579 para subsidiar Marguerite e suas damas, não em uma defesa fideísta do cristianismo, mas como último recurso - uma vez falhada a estratégia

53 POPKIN, 2003, p. 51.

54 Na edição de 1588 Montaigne acrescenta: "[B] É uma tábula rasa [carte blanche] preparada para assumir pelo dedo de Deus as formas que a este aprouver nela gravar" $(506 / 260)$.

55 Diferentemente do discípulo de Montaigne, Charron (2006:68-69), que considera o ceticismo útil para livrar os chineses do paganismo, preparando o terreno para a fé cristã.

56 Posição assumida pelos pirrônicos antigos (PH III, 2) e pelos céticos acadêmicos (De Nat Deo III, 5-6).

57 POPKIN, 2003. p. 90.

58 POPKIN, 2003. p. 103. Para uma crítica à atribuição por Popkin de uma crise pirrônica a Montaigne, ver Ayers (2004: 323-326). Ayers atribui a Montaigne uma metafísica de cunho platônico. 
apologética católica racionalista tradicional que Marguerite deve priorizar - como um antídoto pirrônico contra a apologética calvinista. ${ }^{59}$ Mantenho, portanto, a leitura de Popkin da Apologia como uma arma da Contra-Reforma, mas observando que o oponente protestante não é um dogmático mas um cético acadêmico probabilista filoniano que defende a maior verossimilhança do calvinismo, isto significando para ele uma maior proximidade da verdade comparativamente ao catolicismo.

A arma pirrônica de ataque à razão que constrói verossimilhança deve ser usada somente "na extrema necessidade". Marguerite deve utilizar Sebond e quem mais puder na forma apologética tradicional, isto é, buscando combater os huguenotes no terreno da razão, mostrando a maior verossimilhança da posição católica vis-à-vis a protestante. Como já indiquei, Montaigne afirma ser isto possível em sua resposta à primeira objeção. Mas no caso de a rainha não conseguir contrapor aos argumentos calvinistas argumentos católicos pelo menos tão verossímeis quanto os dos "novos doutores" - e há evidências que indicarei abaixo de que Montaigne considera o calvinismo mais verossímil (mais racional, para a nossa razão finita e falível) do que o catolicismo deverá usar a arma pirrônica disponibilizada por Montaigne para justificar a sua não conversão. Esta arma é a desqualificação da razão como instrumento de aproximação à verdade. $\mathrm{O}$ fato de uma doutrina aparecer verossímil não significa que esteja mais próxima da verdade ou que seja mais provavelmente verdadeira, pois a validade desta verossimilhança concerne exclusivamente à subjetividade humana, nada informando sobre a verdade das coisas.

Emmanuel Naya, num amplo estudo ainda não publicado sobre a influência dos ceticismos antigos no Renascimento, ${ }^{60}$ mostra que o probabilismo acadêmico foi utilizado por apologistas católicos como via para as verdades reveladas. Naya ${ }^{61}$ cita como um exemplo de tal utilização do probabilismo acadêmico o prefácio de Hervet à sua tradução de Sexto dedicada ao grande teórico da Liga, o cardeal de Lorrain (tio e tutor do chefe da Liga, Henri de Guise). Diz Hervet que o exercício cético é "bastante eficaz para estimular e

59 Luiz Eva mantém, detalha e desenvolve amplamente a tese do Montaigne pirrônico, rejeitando a tese do Montaigne fideísta (de forma coerente com o pirronismo antigo) não somente na Apologia (ver Eva 2004), mas nos Ensaios como um todo (ver Eva 2007). Esta minha leitura que enfatiza o aspecto dialético do pirronismo da Apologia não é de forma alguma incompatível com a hipótese de Montaigne ter sido fortemente influenciado pela sua leitura de Sexto, além das outras leituras céticas (de Cícero e de Plutarco) que marcaram profundamente os Ensaios. Na seguinte passagem Montaigne se coloca claramente como cético: "Nous autres, qui privons nostre jugement du droict de faire des arrests, regardons mollement les opinions diverses; et, si nous n'y prestons le jugement, nous y prestons l'oreille” (III, 8, 923). O ceticismo favorece a atividade diplomática exercida por Montaigne junto a Marguerite, Henri de Navarra e Henri III.

60 Ver o resumo da tese publicado em Naya 2009.

61 Ver: Essais de Michel Seigneur de Montaigne, 2006. pp. 35-37. 
aguçar a inteligência dos jovens que, somente então, estarão em condições de distinguir a verdade, pois separarão o que é provável e verossímil do que não o é, e enfim extrairão de muitos prováveis e verossímeis a verdade que ocultavam" $"$. O exame do contexto da Apologia aqui apresentado sugere que este uso apologético da verossimilhança acadêmica foi feito também pelos calvinistas autores da segunda objeção. Verifica-se assim que tanto católicos como protestantes consideraram sua religião mais verossímil do que a do outro, fazendo a mesma apropriação apologética deste probabilismo epistêmico filoniano. Minha leitura concorda com a de Naya no sentido em que este diverge da leitura fideísta de Montaigne proposta por Popkin. Entretanto, não me parece evidente que Montaigne recuse o probabilismo acadêmico a favor do ceticismo pirrônico pela razão de somente o primeiro ser cristianizável ${ }^{63}$. O alvo da Apologia não é a verossimilhança tal como defendida por um Hervet como ponto de partida para a aceitação da revelação cristã, mas o uso desta estratégia pelos protestantes para justificarem a reforma de determinadas crenças cristãs, a saber, os dogmas desprovidos de verossimilhança. A posição de Hervet é a mesma de Agostinho que toma a verossimilhança epistemicamente, isto é, como pressupondo - no caso também apontando para - a verdade. ${ }^{64}$ Montaigne rejeita esta interpretação epistêmica da verossimilhança, mas como a argumentação pirrônica na Apologia tem um alvo bem específico, não podemos dizer se Montaigne rejeita ou não qualquer uso apologético cristão do ceticismo.

Montaigne se dirige a Marguerite poucas páginas antes da crítica à verossimilhança acadêmica. Esta crítica é o núcleo duro do conselho que dá à princesa e compreende o segmento da Apologia em que Montaigne ataca a razão diretamente (339-558-576/365). Montaigne diz que a posição pirrônica é mais coerente do que a acadêmica, retomando contra os acadêmicos a objeção de Agostinho de que o verossímil pressupõe a verdade (tese que para Agostinho era admitida secretamente pelos acadêmicos). ${ }^{65}$ A crítica de Montaigne afasta a interpretação filoniana, restituindo a verossimilhança ao seu significado

62 Ver prefácio de Hervet em Legros 1999:55: "qui tum demum poterunt verum discernere, cum quae sunt probabilia \& verisimilia, ab iis quae secus sunt, dijudicaverint, \& ex multis probabilibus \& verisimilibus latens verum tandem eruerint”. A tradução é de Flávio Loque, Sképsis 2:3-4 (2008): 195.

63 A tese de Naya que somente o ceticismo acadêmico e não o pirronismo seria cristianizável é controversa, mas não cabe aqui examiná-la. Cabe aqui somente ter em mente a diferença entre o probabilismo epistêmico filoniano - este sim claramente cristianizável - do probabilismo meramente prático carneadiano.

$64 \mathrm{O}$ caso do prefácio de Hervet ilustra bem a tese de Naya de que ceticismos diferentes, um conciliável (o acadêmico) outro inconciliável (o pirrônico) com o cristianismo, foram por vezes confundidos ou relacionados por um mesmo autor. Hervet introduz, afinal, sua tradução de Sexto e não uma tradução de Cícero. Mas neste mesmo prefácio aponta o uso anti-protestante do ceticismo pirrônico.

65 Agostinho, C Ac III, 37-43; Conf V, 19. 
original carnediano, segundo o qual há um abismo intransponível entre verossimilhança (que diz respeito ao aspecto da impressão voltada para o sujeito) e conhecimento das coisas (que diz respeito ao aspecto da impressão voltado para o seu objeto). ${ }^{6}$ A rejeição de qualquer valor epistêmico da verossimilhança é coerente com a própria crítica acadêmica ao poder de nossas faculdades de alcançar a verdade. ${ }^{67}$ A precariedade de nossas faculdades (de nossa natureza) determina a precariedade da verossimilhança enquanto instrumento epistêmico. Além disto, o diagnóstico cético desta precariedade recomenda - por razões práticas - a suspensão do juízo, que está de acordo com o ideal de sabedoria acadêmico (na interpretação não dialética da nova academia): se não podemos alcançar a verdade, podemos ao menos evitar o erro não dando o assentimento mesmo ao que parecer plausível (verossímil) para as nossas faculdades.

embora estabelecessem [...] que a verdade está engolfada em profundos abismos [os acadêmicos] admitiam que algumas coisas eram mais verossímeis [vray-semblables] do que outras e admitiam em seu julgamento essa faculdade de se poder inclinar mais para uma aparência do que para outra. [...] Mas como eles se deixam dobrar pela verossimilhança, se não conhecem a verdade? [...] Se nossas faculdades intelectuais e sensíveis não têm fundamento nem base, se não fazem mais que flutuar e girar ao vento, por nada deixemos levar nosso julgamento a alguma parte de sua operação, qualquer que seja a aparência que esta pareça nos apresentar. (562/344 - ênfases adicionadas).

O contexto desta posição é a verossimilhança das doutrinas calvinistas e a inverossimilhança das católicas, tal como argumentadas pelos apologistas huguenotes que frequentavam a corte de Nérac. "Esta facilidade que têm os bons espíritos de tornar plausível [vraysemblable] o que quiserem - e não há nada estranho que eles não se aventurem a dar-lhe cor suficiente para enganar uma simplicidade como a minha - mostra claramente a fragilidade de sua prova" (570/356).$^{68}$ Além do problema da coerência, o probabilismo aparece aqui como inadequado até como critério prático da ação. Como a razão pode construir e desconstruir verossimilhança, esta não constitui um guia estável para a ação. Este é o uso propriamente pirrônico da razão. ${ }^{69}$ Qualquer

66 Ver Sexto, AM VII, 168-169 e Cicero, Ac II, 99-101.

$67 \mathrm{Na}$ edição [C] Montaigne acrescenta uma citação dos Acadêmicos de Cícero: "Inter visa vera aut falsa ad animi assensum nihil interest" (Ac II, 28).

68 Mesmo espíritos menos simples são persuadidos por crenças extremamente verossímeis, como o repouso da terra, que eventualmente se mostram falsas, como nota Montaigne citando o copernicismo.

69 "os pirrônicos utilizam seus argumentos e seu raciocínio apenas para arruinar a aparência da experiência; e é espantoso até onde a flexibilidade de nossa razão seguiu-os nesse intento de combater a evidência dos fatos" (571/358). 
crença, por mais verossímil que seja, poderá ser suspensa, seja graças a habilidade do pirrônico de estabelecer a igual verossimilhança de uma crença contrária, seja, como último recurso quando o pirrônico não consegue estabelecer a equipolência, pelo argumento falibilista que desqualifica epistemologicamente a verossimilhança. "Assim, quando alguma doutrina nova se apresenta a nós, temos muita razão em desconfiar dela e considerar que antes que fosse produzida sua contrária estava em voga; e assim como aquela foi derrubada por esta, no futuro poderá nascer uma terceira invenção que da mesma forma se chocará com a segunda" (570/356-357).$^{70}$ Esta é bem a situação de Marguerite em Nérac, a quem foi apresentada de forma verossímil uma nova doutrina - a calvinista - contra a qual ela não consegue contrapor uma católica igualmente verossímil. Apesar disto, Marguerite não agirá contra a razão mantendo a doutrina que lhe aparece na ocasião menos verossímil. Basta considerar que antes de Calvino as doutrinas católicas eram verossímeis e que poderá surgir novo reformador religioso que mostrará a inverossimilhança das doutrinas calvinistas. Além disto, dada a plasticidade da razão, basta habilidade para as mesmas doutrinas serem sucessivamente mostradas verossímeis e inverossímeis. ${ }^{71}$ Vemos assim que mesmo restituída à sua dimensão exclusivamente prática, a probabilidade acadêmica não deve ser observada em questões fundamentais e controvertidas como a sobre a qual Montaigne aconselha Marguerite. Se a princesa ou Montaigne ou qualquer outro seguisse o verossímil, não pararia de rolar em meio a diferentes seitas, eventualmente retornando e tornando a sair das mesmas seitas em função da contingência de se deparar com apologistas habilidosos das mesmas.

Montaigne cita o seu caso pessoal no aconselhamento à Marguerite.

[A] Ora, do conhecimento dessa minha volubilidade acidentalmente gerei em mim uma certa constância de ideias, e dificilmente tenho alterado as minhas primeiras e naturais, pois qualquer que seja a aparência [quelque apparence] da novidade, não

70 Ver $\mathrm{PHI}$, 33-34.

71 Outro problema ressaltado por Montaigne - retomando os Acadêmicos de Cícero (Ac II.8) - é a grande influência de fatores não epistêmicos na formação das crenças. A verossimilhança não necessita de boas razões. Fatores fortuitos, não epistêmicos, podem conferir verossimilhança às crenças. Na Apologia, Montaigne cita uma variação que sofreu decorrente de uma paixão juvenil (569/354-355). No ensaio "Da Virtude", mostra isto na religião: "Um personagem, grande em anos, em renome, em dignidade e ciência, gabava-se a mim de ter sido levado a uma certa mudança muito importante de sua fé por uma incitação externa tão bizarra e de resto tão pouco conclusiva que a achei mais forte ao contrário: ele a chamava de milagre e eu também, mas em sentido diferente" (II, 29,710/565). O exemplo mais relevante é a influência das conversas nas alcovas das damas nas decisões de grandes conferências político-religiosas: "Nossas maiores agitações têm motivações e causas irrisórias [...] em minha época vi as mais sábias cabeças deste reino reunidas, com grande cerimônia e despesa pública, para tratados e acordos cuja verdadeira decisão, porém, dependia soberanamente das conversas no toucador das senhoras e da disposição de alguma mulherzinha" (III, 10, 1018/351). 
mudo facilmente, pelo medo que tenho de perder na troca. E, posto que não sou capaz de escolher, tomo a escolha de outrem e mantenho-me na posição em que Deus me pôs. De outra forma eu não conseguiria impedir-me de ficar rolando sem parar. Assim, pela graça de Deus, conservei-me intacto [...] nas antigas crenças de nossa religião, em meio de tantas seitas e divisões que nosso século produziu. (569/355 ênfases adicionadas).

Montaigne provavelmente se refere a um dilema pessoal que viveu em algum momento de sua vida. Se se tivesse guiado pela verossimilhança na querela religiosa ter-se-ia, como a sua mãe e irmãos, convertido ao calvinismo. ${ }^{72}$ No ensaio I, 27/“"É loucura condicionar ao nosso discernimento o verdadeiro e o falso", podemos entender melhor porque Montaigne pode permanecer católico sem problema de consciência mesmo verificando a maior verossimilhança de pelo menos algumas doutrinas calvinistas. Diz que "é uma tola presunção ir desdenhando e condenando como falso o que não nos parece verossímil; esse é um vício habitual nos que pensam ter algum discernimento além do comum [como os novos doutores da corte de Nérac]. Outrora eu agia assim". O caso relevante é citado no final do ensaio: o problema da Reforma.

Ora, o que me parece trazer tanta desordem a nossas consciências, nesses distúrbios religiosos em que estamos, é essa dispensa que os católicos fazem de sua fé. Parece-lhes que agem como moderados e sensatos quando cedem aos adversários alguns artigos dos que estão em debate. Mas, além de não verem quanta vantagem dá a quem vos ataca começardes a ceder-lhes e recuardes, e como isso o anima a prosseguir sua investida, esses artigos que eles escolhem como os de menor peso são às vezes muito importantes. Ou é preciso submeter-se totalmente à autoridade de nossa política eclesiástica, ou dispensá-la totalmente. Não cabe a nós estabelecer a parcela de obediência que lhe devemos. E mais ainda: posso dizê-lo porque o experimentei, tendo outrora usado essa minha liberdade pessoal de escolha e seleção para negligenciar certos pontos da observância de nossa Igreja que parecem ter um aspecto mais vão ou mais estranho e vindo a falar disso com os homens sábios, descobri que tais coisas têm um fundamento maciço e muito sólido e que apenas a tolice e a ignorância nos fazem recebê-las com menos respeito que ao restante. Por que não lembrarmos quanta contradição sentimos em nosso próprio discernimento?

72 No ensaio "Das orações" (I, 56) Montaigne deixa entrever a associação feita no meio culto entre catolicismo e superstição. "Como me parecia fantástica a imaginação dos que, nestes anos passados, costumavam criticar qualquer um em quem reluzisse alguma clareza de espírito, professando a religião católica, que era por fingimento, e acreditavam mesmo, para honrá-lo, que não importa o que ele dissesse exteriormente, por dentro não podia deixar de ter sua crença reformada na medida da deles. Doença irritante, a de se acreditar tão forte a ponto de convencer-se de que não é possível acreditar no contrário! $E$ ainda mais irritante porque a pessoa se persuade de que um determinado espírito prefere não sei qual disparidade de fortuna atual às esperanças e ameaças da vida eterna. Eles podem acreditar em mim. Se algo tivesse tentado minha juventude, a ambição do risco e dificuldade que acompanhavam esse recente empreendimento teria tido boa parte nisso" (I, 56, 320/477). Montaigne prefere seguir a segurança da tradição católica do que a maior verossimilhança da doutrina calvinista. Por causa do seu catolicismo foi taxado de supersticioso. (II, 17/"Da presunção", 471). 
Quantas coisas ontem nos serviam de artigos de fé e hoje nos são fábulas? (I, 27, 181-182/271-272).

Este souvenir pessoal remete ao trecho da Apologia sobre a mutabilidade da razão.

Quando me pressionam com um novo argumento, cabe a mim estimar que aquilo a que não puder satisfazer, um outro satisfará; pois acreditar em todas as aparências das quais não nos podemos livrar é uma grande ingenuidade. Dessa forma aconteceria que todos os homens comuns [...] veriam sua convicção girando facilmente, como um cata-vento, pois sua alma, sendo maleável e sem resistência, seria forçada a acolher incessantemente outras impressões, a última apagando sempre o rastro da anterior. (570-571/357).

Passagens como esta desta parte da Apologia embasam as leituras do ceticismo de Montaigne feitas por Giocanti e Brahami, segundo as quais Montaigne romperia com a epoche em função da incapacidade antropológica humana de resistir ao verossímil. Pois é justamente a posição contrária que Montaigne defende aqui: trata-se de resistir ao verossímil - ao menos em questões cruciais em que a vida ou salvação estão em jogo, como é o caso, respectivamente, da medicina e da religião. ${ }^{73}$ Em questões menos importantes que não são objeto de controvérsia, podemos seguir nossa inclinação natural e aderir ao verossímil, cuja força é reconhecida por Montaigne. ${ }^{74}$ Somente espíritos fortes são capazes de resistir-lhe ${ }^{75}$ - como dirá Charron pouco depois $-{ }^{76}$ e é por isso que Montaigne recomenda um uso muito circunstanciado e secreto da estratégia pirrônica. Note que por "razão" aqui Montaigne entende "esta aparência de raciocínio [discours] que cada qual forja em si - essa razão por cuja condição pode haver cem raciocínios contrários em torno de um

73 Para outras críticas a Brahami, ver Cardoso (2009) e Birchal (2007: 80ff).

74 Esta força transparece no contexto mesmo da contraposição das duas escolas céticas antigas quando Montagine diz que a posição pirrônica é a mais "verossímil" (506/260) no que concerne às relações entre razão e fé, quando diz que os acadêmicos "consideravam demasiadamente grosseiro dizer que não era mais verossímil que a neve fosse branca do que preta" (561/343) e ao concluir que "a opinião dos pirrônicos é mais ousada e ao mesmo tempo mais verossímil” (561/344).

75 Obras de controvérsia foram escritas por católicos como Gabriel de Boissy para, afirma o autor, "servir aux catholiques qui demeurent en mesme lieu que les Religionnaires et qui sont obligéz de converser avec eux. L'expérience fait voir que le commun des catholiques est ordinairement très peu instruit des véritez de la Foy et mesmes plusieurs de ceux qui en ont quelque instruction ne s'estiment pas assez forts pour oser se commettre de résister à l'erreur. De là il arrive que les Religionnaires qui aiment toujours à parler, surtout lorsqu'ils perçoivent qu'on ne dit mot, entretiennent seuls les compagnies et proposent cent difficultez contre nos créances, pour donner des scrupules aux faibles et faire trophée de la vérité qu'ils n'ont pas» (citado por Kappler 2001: 243-244, ênfases adicionadas).

76 Esta resistência à verossimilhança, apesar da forte inclinação natural que temos em sua direção, será central na dúvida cartesiana. Ver meu artigo "Rationalisme critique académicien chez Montaigne et Descartes», a ser publicado em número especial da Montaigne Studies sobre Montaigne e Descartes. 
mesmo assunto, é um instrumento de chumbo e de cera, alongável, dobrável e adaptável a todas as perspectivas e a todas as medidas; é preciso apenas a habilidade de saber dar-lhe contorno" (565/349). Esta é a razão que constrói verossimilhanças. A ela Montaigne opõe a pirrônica, que se vale desta mesma maleabilidade, não para construir mas para destruir a verossimilhança que impede a suspensão do juízo. Marguerite deve fazer como Montaigne, não se deixar levar pela verossimilhança das doutrinas calvinistas nem se afastar do catolicismo pela inverossimilhança de algumas de suas doutrinas. Antes de Nérac doutrinas católicas pareciam verossímeis a Marguerite, católica convicta. Em Nérac, exposta aos apologistas huguenotes, algumas destas mesmas doutrinas agora lhe aparecem inverossímeis. Mas se Marguerite se converter por causa disto - ato que teria enorme repercussão na politica francesa da época - poderá eventualmente, após retornar ao Louvre e se expor novamente a habilidosos apologistas católicos, voltar a considerar as doutrinas rejeitadas como mais verossímeis. Deve portanto desconsiderar a verossimilhança. Mudanças tão radicais e monumentais como as deslanchadas pela Reforma - seja dos grandes do reino, seja de multidões dos povos (que vão atrás dos grandes) - são incompatíveis com a natureza do estado, como diz Montaigne, este grande corpo que se sustenta somente pelo seu próprio peso. $^{77}$

\section{Referências bibliográficas}

AgOstinHO (2008). Contra os Acadêmicos [C. Ac]. Trad. Agustinho Belmonte. São Paulo: Paulus [Coleção Patrística, vol. 24].

AYERS, Michel (2004). "Popkin's Revised Scepticism", British Journal for the History of Philosophy 12 (2): 319-332.

BIRCHAL, Telma (2007). O Eu Nos Ensaios de Montaigne. Belo Horizonte: Editora UFMG. BOLZANI FILHO, R. (2003). Acadêmicos versus Pirrônicos. Tese de Doutorado inédita, USP.

CARDOSO, Sérgio (2009). « On Skeptical Fideism in Montaigne's Apology for Raymond Sebond" in Maia Neto, J. R.; Paganini, G. e Lauser, J. C. (orgs.) Skepticism in the Modern Age. Building on the work of Richard Popkin. Leiden: Brill, pp. 71-103. BRAHAMI, Frédéric (2001). Le Travail du Scepticisme : Montaigne, Bayle, Hume. Paris: PUF.

77 "Nem tudo o que balança cai. A contextura de um corpo tão grande depende de mais de um prego. Ele resiste até mesmo por sua antiguidade - como os velhos edifícios cuja base a idade solapou, sem revestimento e sem argamassa, que no entanto vivem e se sustentam em seu próprio peso" (III, 9, 960/262 - "Da Vanidade"). 
CHARRON, Pierre (2006). Pequeno Tratado de Sabedoria. Trad. Maria Célia Veiga França. Belo Horizonte: Editora UFMG.

CICERO, Marcus Tulius. De Natura Deorum [Nat Deo] and Academica [Ac]. Trad. H. Rackham (Loeb Classical Library). Cambridge, MA: Harvard U. Press, 1944.

COPPIN, Joseph (1923). "Marguerite de Valois et le Livre des Créatures de Raymond Sebond", Revue du Seizième Siècle 10: 57-66.

DROZ, Eugene (1964). «La Reine Marguerite de Navarre et la vie littéraire à la cour de Nérac (1579-1582)», Extraits du Bulletin no. 80 de la Societé des Bibliophiles de Guyenne. Bordeaux : Imprimerie Taffard.

EVA, Luiz (2004). Montaigne contra a vaidade. Um estudo sobre o ceticismo na Apologia de Raymond Sebond. São Paulo: Humanitas.

EVA, Luiz (2007). A Figura do Filósofo. Ceticismo e subjetividade em Montaigne. São Paulo: Loyola.

FEBVRE, Lucien (1942). Le Problème de l'incroyance au XVIe siècle. La religion de Rabelais. Paris: A. Michel.

FÓCIO (1962). Bibliothèque. Vol. 2. Tr. R. Henry. Paris: Les Belles Lettres.

GIOCANTI, Sylvia (2001). Penser l'irrésolution. Montaigne, Pascal, La Mothe Le Vayer. Trois itineraires sceptiques. Paris: H. Champion.

GRÜEN, Alphonse (1855). La vie publique de Michel de Montaigne. Paris: Amyot. GUY, Alain (1990). «La Theologia Naturalis en son temps : structure, portée, orgines» in C. Blum (org.) Montaigne. Apologie de Raimond Sebond. De la Theologia à la Théologie (Paris: Honoré Champion), pp. 13-47.

HERVET, Gentien (2008). «Dedicatória - Prefácio de G. Hervet a sua tradução do Adversus Mathematicos", tradução de Flávio Loque, Sképsis 2 (3-4): 193-196.

KAPLER, Émile (2011). Les Conférences théologiques entre catholiques et protestants en France au XVIIe siècle. Paris: Honoré Champion.

KRISTELLER, Paul O. (1968). «The Myth of Renaissance Atheism and the French Tradition of Free Thought», Journal of the History of Philosophy 6: 233-243.

LEGROS, Alain (1999). "La Dédicace de l'Adversus Mathematicos au Cardinal de Lorraine ou du bon usage de Sextus Empiricus selon Gentien Hervet et Montaigne », Bulletin de la Societé des Amis de Montaigne 15-16: 51-72.

LENNON, Thomas (2008). The Plain Truth. Descartes, Huet, and Skepticism. Leiden: Brill. LEVY, Carlos (2001). "Pierre de Valence, historien de l'Académie ou académicien?» in Moreau, P-F. (org.). Le scepticisme au XVIe et au XVII siècle. Paris : Albin Michel, pp. 174-187.

LIMBRICK, Elaine (1990). "Metamorphose d'un philosophe en theologien" in C. Blum (org.) Montaigne. Apologie de Raimond Sebond. De la Theologia à la Théologie (Paris: Honoré Champion), pp. 229-246.

LOQUE, Flávio (2012). Ceticismo e Religião no Início da Modernidade. A Ambivalência do Ceticismo Cristão. São Paulo: Loyola.

MAIA NETO, José (1997). «Academic Skepticism in Early Modern Philosophy», Journal of the History of Ideas 58: 199-220. 
MAIA NETO, José (1999). "Bayle's Academic Skepticism" in Force, J. and Katz, D. (orgs.) Everything Connects. In conference with Richard Popkin. Leiden: Brill, pp. 264-275.

MAIA NETO, José (2003). “Foucher's Academic Cartesianism” in Lennon, T. (org.) Cartesian Views. Papers presented to Richard A. Watson. Leiden: Brill, pp. 71-95.

MAIA NETO, José (2009). «Charron's Academic Skeptical Wisdom» in Paganini, G. e MAIA NETO, J. (orgs.), pp. 213-227.

MAIA NETO, J. "Rationalisme critique académician chez Montaigne et Descartes", Montaigne Studies (no prelo).

MONTAIGNE, Michel de (2004). Les Essais. Ed. Villey-Saulnier. Nouvelle édition en 1 volume. Paris: Quadrige/PUF.

MONTAIGNE, Michel de (2000-2001). Os Ensaios. Ed. P. Villey. Tradução Rosemary C. Abílio. 3 vols. São Paulo: Martins Fontes.

NAKAM, Géralde (1993). Montaigne et son temps. Paris: Gallimard.

NAYA, Emmanuel (2006). Essais de Michel Seigneur de Montaigne. Paris : Ellipses.

NAYA, Emmanuel (2008). "Le 'coup de Talon' sur l'impieté: scepticisme et vérité chrétienne au XVIe siècle», Les Études Philosophiques. Paris: PUF, pp. 141-160.

NAYA, Emmanuel (2009). «Renaissance Pyrrhonism: A Relative Phenomenon» in Paganini, G. e Maia Neto, J. (orgs.) Renaissance Scepticisms (Dordrecht: Springer, 2009), pp. 13-32.

NORTON, Grace (1904). Studies in Montaigne. New York: Macmillan.

PAGANINI, Gianni e MAIA NETO, José (orgs.) (2009). Renaissance Scepticisms. Dordrech: Springer.

POPKIN, Richard (1960). The History of Scepticism from Erasmus to Descartes. Assen: Van Gorcum.

POPKIN, Richard (2003). The History of Scepticism from Savonarola to Bayle. Oxford: Oxford U. Press.

RIGOLOT, François (1990). 'D'une Theologie 'pour les dames' a une Apologie 'per le donne'?" in Blum, C. (org.) Montaigne. Apologie de Raimond Sebond. De la Theologia à la Théologie (Paris: Honoré Champion), pp. 261-290.

SEBON, Raymond (1569). La Theologie naturelle. Trad. Michel de Montaigne. Paris: Toussaints du Bray.

VIENNOT, Eliane (2005). Marguerite de Valois. «La reine Margot». Paris: Perrin (1a. ed. 1993)

VILLEY, Pierre (1933). Les sources et l'évolution des Essais de Montaigne. 2 vols. Paris: Hachette (segunda edição).

WOOTON, David (1988). «Lucien Febvre and the Problem of Unbelief in the Early Modern Period", Journal of Modern History 60: 695-730. 